\title{
Where do the data come from?
}

\author{
J. Hadjigeorgiou Lassonde Institute of Mining, University of Toronto, Canada
}

\section{Abstract}

Deep and high stress mining poses a significant number of geotechnical challenges. Despite considerable improvements in almost every technological aspect of the design and operation of mines at depth and under high stress, the weakest link remains the quality and quantity of data. This paper addresses certain inconvenient facts on how data are collected and managed. The case is made for a disciplined approach to data collection, analysis and interpretation. Unless this is implemented in a systematic way, it will not be possible to capitalise in gains made from improved engineering tools. A further concern is that for mines operating at depth, the margin of error due to inadequate or inappropriate data is much smaller, and the repercussions more severe, compared to shallow mines.

\section{Introduction}

The need for data is neither new nor restricted to mining. An eloquent description for the need for data is provided by Doyle (1892). In the book "A Scandal in Bohemia", the fictional detective Sherlock Holmes advises Dr Watson that:

"It is a capital mistake to theorize before one has data. Insensibly one begins to twist facts to suit theories, instead of theories to suit facts."

In a rock mechanics context the need for geotechnical data was articulated by Hoek (1994). In a letter to the International Society of Rock Mechanics (ISRM) News Journal he provided a sobering commentary:

"I see almost no research effort being devoted to the generation of the basic input data which we need for our faster and better models and our improved design techniques. These tools are rapidly reaching the point of being severely data limited."

Although we have made significant strides in certain areas of data collection, the above sentiment is still of pertinence today. This paper stems from personal observations over the years that suggest that quite often there is no clear understanding where geomechanical data come from, how they are used, and how they will eventually find their way into reports and PowerPoint slides. This is crucial as critical design decisions are generally based on geomechanical data.

Collecting geomechanical data is not an objective in itself. Unless they can be analysed and summarised, they remain of limited use. In order to be useful, data have to be processed and converted into information. In a deep mining context it may very well be that, depending on the level of detail required, one person's information is another person's data. The results of rock mass characterisation, i.e. material properties, can be processed into classification systems that can be converted into knowledge in the form of a geomechanical model. This knowledge is in fact part of the necessary data that provide appropriate input for numerical and empirical design tools. This process is completed when information is transformed into knowledge. This could be the identification of areas within a mine that are susceptible to instability or require change in mining strategy, ground support, etc. This process is successful if the contributing parties are experienced in their tasks but also educated to gain a clear understanding of the interdependence of all processes.

The thesis of this paper is that understanding the limitations of data collection techniques and geomechanical data management are important in the design of all mining excavations. In deep and high stresses mining, however, the severity of challenges faced by the mines allow little tolerance for mishandling or misinterpreting geomechanical data. 


\section{The need for data in engineering design}

A rational approach in the design of mining excavations would require clearly defined engineering objectives. The primary objectives being the economic and safe extraction of ore under what may be difficult ground conditions. It is consequently surprising that, given our improved understanding of the major issues in rock engineering, there has not been more work in formalising the design process.

A notable exception is the work of Bieniawski (1992) who identified the following design principles for rock engineering:

- clarity of design objectives and functional requirements

- minimum uncertainty of geological conditions

- simplicity of design components

- state-of-the-art practice

- optimisation

- constructability.

In his work, Stacey (2004) explored the link between the design process in rock engineering and the code of practice to mitigate rock fall and rockburst accidents and later on, suggested a distinction between defining and executing the design. This was illustrated in "the engineering circle" where the first phase (defining the design) contains four steps and the second (executing the design) six steps (Figure 1).

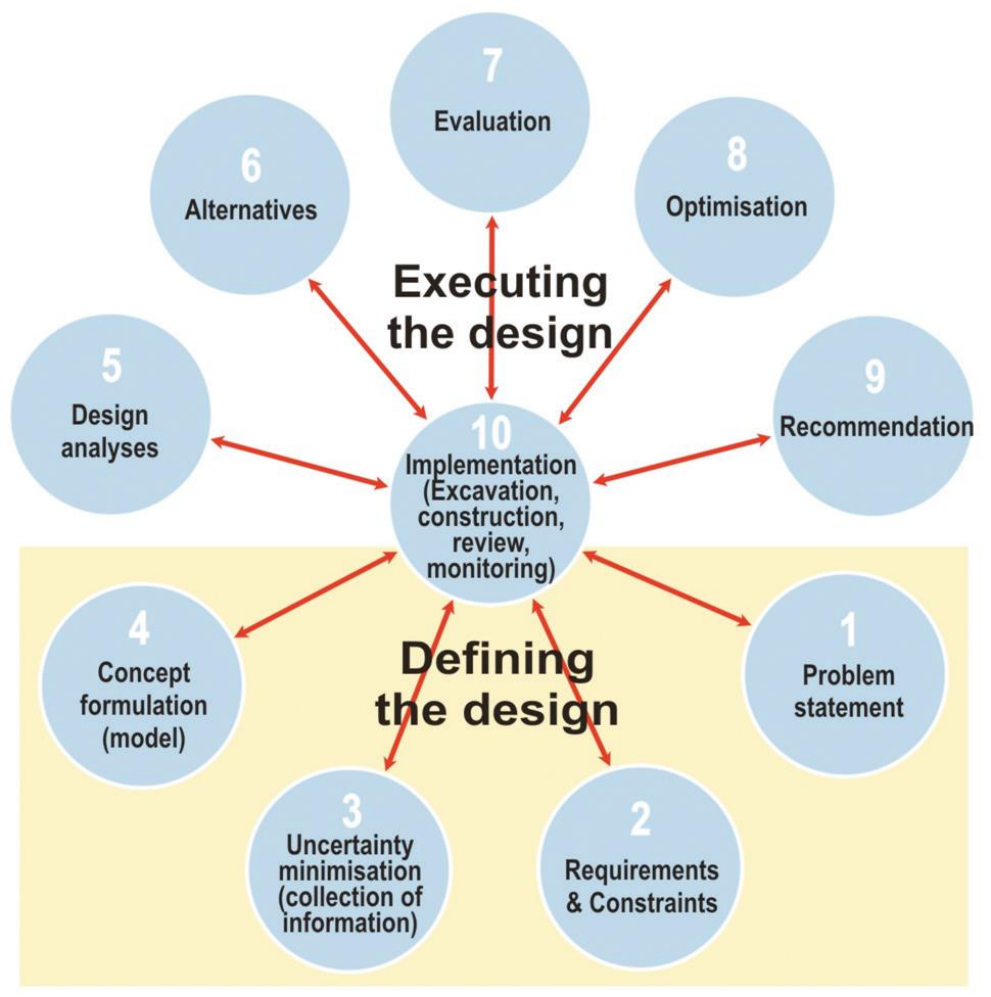

Figure 1 The engineering circle, after Stacey (2009)

Irrespective of whether the process is described as minimising uncertainty or otherwise, there is a need for geomechanical data collection. For example, Bieniawski (1988) suggested that:

".....geological and rock mechanics data must be collected in sufficient quantity and of high quality; data interpretation should be performed specifically for purposes of engineering design; and innovative design approaches should be used to bring about improvements in productivity and safety". 
This is further echoed by Stacey (2009) who identified the data collection process as one of uncertainty minimisation. In this context, the aim is to collect data to enable defining the following: rock materials present; rock mass structure; rock mass geotechnical zones and strength properties of rock/rock mass.

A further distinction has been presented by Hadjigeorgiou and Harrison (2011), where uncertainty and sources of error were identified as two different components of engineering analysis and design. In this approach, sources of error are associated with data collection and material testing methods. Baecher and Christian (2003) make a distinction between uncertainty due to naturally variable phenomena in time or space and that due to lack of knowledge or understanding.

\section{$3 \quad$ Analysis and design}

In a deep mining context, there is a need to construct geological and geomechanical models, employ classification systems, build structural models and assess the necessary input data into a 3D numerical stress analysis model. All these processes have different data requirements. Unless these needs are understood and communicated to the personnel responsible for data collection, this information is missed.

In all conceptual design diagrams, data collection precedes analysis and design. This sequential process may be appropriate and applicable in civil engineering projects but it is not necessarily the case in deep mining projects. In a mining context, what is more applicable is a continuous process where several of the steps are either run in parallel or through several iterations, i.e. closing the design loop.

A further issue, sometimes overlooked, is that the engineering design process has become tool driven. Therefore, unless there is a clear understanding, a priori, of the input data needed to apply these tools, the required data will invariably not be collected. As a result, further data collection campaigns may become necessary or alternatively the gaps are tentatively filled by extrapolating available data.

\section{1 Rock mass classification systems}

Rock mass classification is one of the only approaches for estimating large-scale rock mass properties. In mining, the Q classification system proposed by Barton et al., (1974) and rock mass rating (RMR) developed by Bieniawski (1976), form the basis of many empirical design methods. As well, they are often used towards defining failure criteria in numerical modelling programs. Rock mass classification systems have evolved as engineers have attempted to apply them to a wider range of engineering problems.

An example of the need for specific data is the use of classification systems. The role of classification is generally to get a better overview of a phenomenon, or set of data, in order to understand them or to take different actions concerning them. Stille and Palmström (2003) have argued that the term "rock mass classification systems" is in fact misleading, as the traditional systems are in fact empirical design methods based on characterisation of rock masses.

Invariably it is not feasible to collect all possible data. On the other hand, if data are collected specifically for one classification system, they may not be adequate for another. In practice it is commonly observed that a mine or a consulting company have a certain affinity or preference for a particular classification system or a version of the system. If the raw characterisation data are used for classification, then the classification ratings become the new data. Depending on the system used, the results can be quite different. Examples of these are the application of both versions of RMR R $_{76}$ (Bieniawski, 1976) and RMR R $_{89}$ (Bieniawski, 1989). Even within the same project it appears that the systems are often used almost interchangeably. Similar disparities are also related to the use of the $Q$ system. The 2002 version, Barton (2002), can result in significant variations in the the ratings for faulting, for strength/stress ratios in hard massive rocks, for squeezing or for swelling (Stress Reduction Factor), as compared to the 1974 version proposed by Barton et al. (1974). A slightly different issue is the use of the Mining Rock Mass Rating (MRMR), which was developed for caving assessment but is now applied to a new range of applications, Jakubec and Laubscher (2000). Irrespective of the merits of MRMR, the reality is that there is less wealth of experience in the use of MRMR as opposed to the RMR and $Q$ systems. The GSI system has received 
increased attention in recent years but it also has a series of limitations as reported by Marinos et al. (2007).

It should be remembered that the basic assumption of the classification systems is that the rock mass contains a sufficient number of "randomly" oriented fractures that it can be treated as a homogeneous isotropic mass. Consequently, rock mass classification systems may be inappropriate for rock masses with dominant structural orientation such as foliation.

The LaRonde Mine further provides several examples where the structural anisotropy and inhomogeneity in a rock mass were taken into consideration in data collection and interpretation. Mercier-Langevin and Hadjigeorgiou (2011) demonstrated that structure was arguably the single most important factor to the onset of squeezing at the site (Figure 2). This requires an investment in constructing representative structural models at the site.
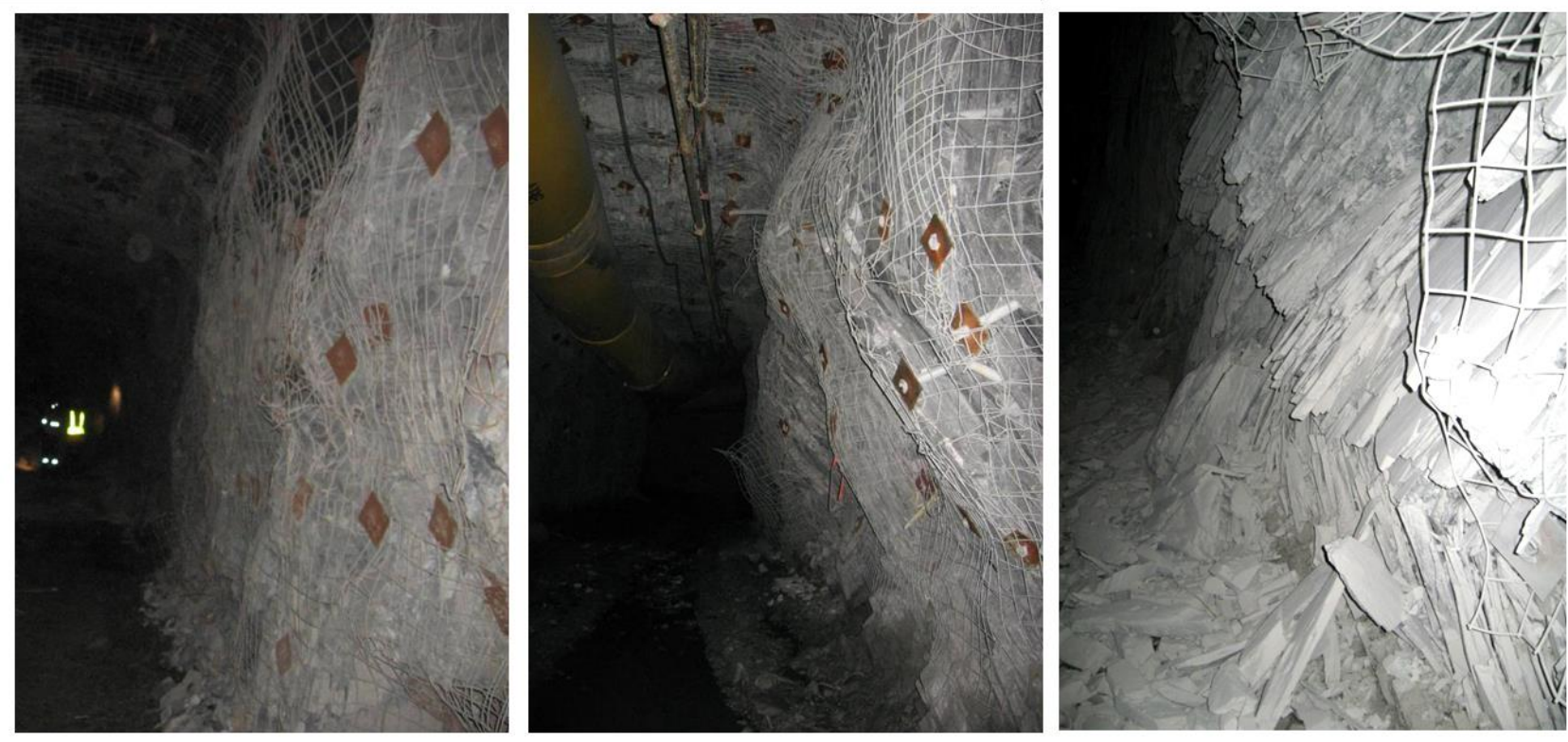

Figure 2 Variations in squeezing severity at locations less than $200 \mathrm{~m}$ apart at $2,300 \mathrm{~m}$ depth as a function of foliation thickness, after Mercier-Langevin and Hadjigeorgiou (2011)

\section{2 Discrete fracture networks}

Recent years have seen a concerted effort to the use of Discrete Fracture Modelling (DFM) and Discrete Fracture Networks (DFN) as part of engineering design in underground mines. Hadjigeorgiou et al. (1995) used DFN to determine in situ block size while Grenon and Hadjigeorgiou (2003) linked DFN to limit equilibrium wedge stability analysis. Examples of linking DFN to stress analysis have also been reported by Pine et al. (2006), Hadjigeorgiou et al. (2009) and Elmo and Stead (2010).

The success of DFN, however, is dependent on the availability of quality geotechnical data. The generation of DFN intensity data together with fracture orientation and spacing are required to develop a representative DFN model (Figure 3). Golder Associates (2009) has identified the necessary measures of fracture intensity data (Table 1). This information, however, is rarely included in the standard data collection process and as such, limits the future application of this type of advanced rock mass modelling technique. 


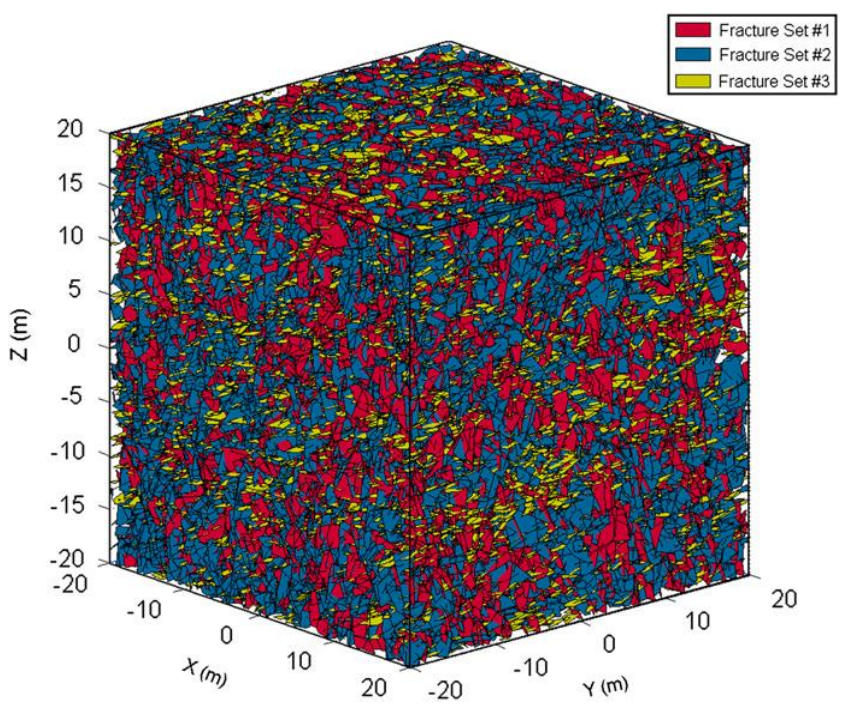

Figure 3 Visualisation of a generated fracture system for Brunswick Mine, after Esmaieli et al. (2010)

Table 1 Measures of fracture intensity, after Golder Associates (2009)

\begin{tabular}{|c|c|c|c|c|c|c|}
\hline & \multicolumn{5}{|c|}{ Dimension of Feature } \\
\hline & & 0 & 1 & 2 & 3 & \\
\hline \multirow{8}{*}{ 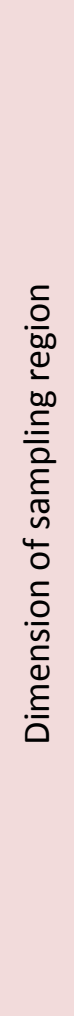 } & 0 & P00 Length ${ }^{0}$ & & & & Point \\
\hline & & Number of fractures & & & & Measure \\
\hline & 1 & P10 Length ${ }^{-1}$ & P11 Length ${ }^{0}$ & & & Linear \\
\hline & & $\begin{array}{l}\text { Number of fractures } \\
\text { per unit length of } \\
\text { scanline (frequency } \\
\text { of linear intensity) }\end{array}$ & $\begin{array}{l}\text { Length of fractures } \\
\text { intersects per unit } \\
\text { length of scanline }\end{array}$ & & & Measure \\
\hline & 2 & P20 Length ${ }^{-2}$ & P21 Length ${ }^{-1}$ & P22 Length ${ }^{0}$ & & Areal \\
\hline & & $\begin{array}{l}\text { Number of traces } \\
\text { per unit area of } \\
\text { sampling plane } \\
\text { (areal density) }\end{array}$ & $\begin{array}{l}\text { Length of fracture } \\
\text { traces per unit } \\
\text { area of sampling } \\
\text { plane (areal } \\
\text { intensity) }\end{array}$ & $\begin{array}{l}\text { Area of fractures } \\
\text { per unit area of } \\
\text { sampling plane }\end{array}$ & & Measure \\
\hline & 3 & P30 Length ${ }^{-3}$ & & P32 Length ${ }^{-1}$ & P33 Length ${ }^{-2}$ & Volumetric \\
\hline & & $\begin{array}{l}\text { Number of fractures } \\
\text { per unit volume of } \\
\text { rock mass } \\
\text { (volumetric density) }\end{array}$ & & $\begin{array}{l}\text { Area of fractures } \\
\text { per unit volume } \\
\text { of rock mass } \\
\text { (volumetric } \\
\text { intensity) }\end{array}$ & $\begin{array}{l}\text { Volume of } \\
\text { fractures per } \\
\text { unit volume of } \\
\text { rock mass }\end{array}$ & Measure \\
\hline
\end{tabular}

In particular, the extension of DFN to construct Synthetic Rock Mass (SRM) models offers several opportunities in design. Recent applications include the work of Cundall et al. (2008), Esmaieli et al. (2010), Elmo et al. (2011), Mas Ivars et al. (2011) and Beck et al. (2009). The potential of this powerful technique is, however, limited if there is no similar effort in collecting the necessary structural data at the engineering scale of a project, for example, drift or stope size. Furthermore, SRM models are also subject to the same issues of data calibration and validation as other techniques. 


\section{3 Stress analysis models}

A necessary input for stress analysis models is the strength of the rock mass. This is often derived through laboratory tests on intact rock samples and some form of extrapolation strategy for large scale samples that incorporate the presence of defects. This is often through the use of empirical relationships based on rock mass classifications schemes. Consequently, it is important to keep these requirements in mind when designing a data collection campaign. It follows that it makes sense to collect the information that would be best suited for these empirical relationships.

In several cases representative models are only possible if the structural geology, including large structures, is explicitly modelled. Cosgrove and Hudson (2011) provided a series of examples of the importance of geological data in establishing rock mechanics properties and the importance of the size of the engineering project.

The importance of structural geology in a mining context is evident in the Doyon-Bousquet-LaRonde district in Québec, which is home to several mines (Figure 4). The area is characterised by many fault zones with the Cadillac fault dominating the geology. From a mine design perspective, it was only possible to provide a plausible explanation of the stress regime once this was taken in to consideration. The impact of structure on stress predictions, with particular emphasis on the Cadillac Fault, has been discussed by Corthésy et al. (1998).

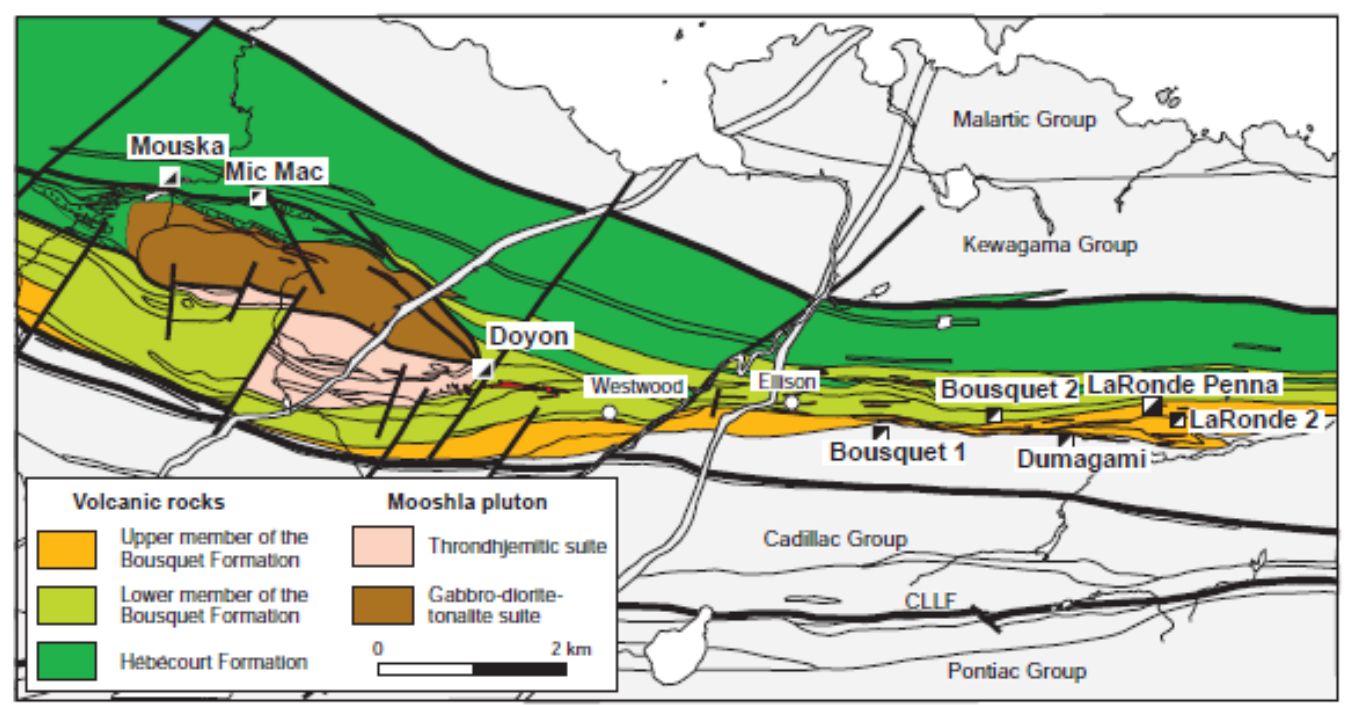

Figure 4 Simplified geological map of the Doyon-Bousquet-LaRonde district showing the main geological features and mine locations. CLLF is the Cadillac-Larder Lake Fault, after Dube et al. (2003)

In deep mines one of the observed burst mechanisms, along with strain and pillar bursts, is slippage along a fault. Despite research efforts in modelling the fault slip mechanism, one of the greater concerns, is our limitation in establishing the presence, geometry and properties of such structures. It is reflected in the colloquial terms used to describe the uncertainty in defining these structures, by referring to "silent" or "ghost" faults.

\subsection{Classifying geotechnical models according to the level of understanding of their geotechnical environment}

It is evident that the quality and quantity of data is defined by the design objectives and functional requirements. In a mining context, this is further qualified by the timeline of the operation from preliminary feasibility, feasibility, development, early production, late production and mine closure. Bullock (2011) provides a series of geotechnical activity definitions from the preliminary to final feasibility stages. 
From a geotechnical perspective, the early stages are often characterised with both limited data and large variations on how data are collected and by whom. It is unfortunate that this information is often disjointed, and reporting of geotechnical data is often quite variable even within mining and consulting companies. The usual justifications for these omissions and lack of conformity are the lack of human resources, costs or simply failure to see the pertinence for this work. This, however, is in sharp contrast to reporting of mineral resources and ore reserves where there are clear guidelines, for example the Canadian and Australian standards of disclosure and reporting mineral reserves, CIM (2005), JORC (2004).

Haile (2004) made a compelling case for the establishment of a framework for classifying geotechnical models according to the level of understanding of their geotechnical environment. Under this approach a geotechnical model can be described as:

- Implied: i.e. with a low level of reliability, with only global estimates of geotechnical characteristics being available.

- Justified: i.e. with a high level of confidence in the intrinsic spatial variability of geotechnical characteristics.

- Verified: i.e. based on in situ knowledge of the rock mass, which provides a reliable model of the intrinsic variability of geotechnical characteristics.

Table 2 clarifies the proposed data interpretation requirements from the implied to the verified stage, and Table 3 suggests guidelines for what rock mass data should be collected.

Table 2 Reporting framework of general requirements and geotechnical model reliability for geotechnical projects, after Haile (2004)

\begin{tabular}{ll}
\hline Data Type & General Requirements and Geotechnical Model Reliability \\
\hline Implied & No site-specific geotechnical data necessary \\
Qualified & $\begin{array}{l}\text { Project-specific data are broadly representative of the main geological units and inferred } \\
\text { geotechnical domains, although local variability or continuity cannot be reliably accounted } \\
\text { for. Project-specific data are of sufficient spatial distribution (density) to identify } \\
\text { geotechnical domains and to demonstrate continuity and variability of geotechnical } \\
\text { properties within each domain }\end{array}$ \\
Justified & $\begin{array}{l}\text { Project-specific data are of sufficient spatial distribution (density) to identify geotechnical } \\
\text { domains and to demonstrate continuity and variability of geotechnical properties within } \\
\text { each domain }\end{array}$ \\
Verified & Site-specific data are derived from local in situ rock mass \\
\hline
\end{tabular}

Table 3 Reporting framework of rock mass data for geotechnical projects, after Haile (2004)

\begin{tabular}{lll}
\hline $\begin{array}{l}\text { Rock Mass } \\
\text { Data }\end{array}$ & Discontinuity & $\begin{array}{l}\text { Intact Material Strength and Deformation } \\
\text { Characteristics }\end{array}$ \\
\hline Implied & Based on general rock type characteristics & Based on general rock type characteristics \\
Qualified & $\begin{array}{l}\text { Estimates of RQD/fracture frequency (FF) } \\
\text { and number of defect sets from resource } \\
\text { data (will probably contain directional bias) }\end{array}$ & $\begin{array}{l}\text { Multi directional FF from in situ mapping and } \\
\text { visual count of defect sets }\end{array}$ \\
Justified & $\begin{array}{l}\text { RQD/FF statistics and number of defect sets } \\
\text { representative of all geotechnical domains } \\
\text { and directions }\end{array}$ & Field and laboratory estimates and variability \\
Verified & $\begin{array}{l}\text { Site-specific data are derived from local in } \\
\text { Mield and laboratory estimates }\end{array}$ \\
\hline
\end{tabular}


situ rock mass

The reality is that at the early stages there is no clear understanding, nor consensus on what will be the use of some of the data. This is understandable to some degree in that the needs may evolve over time. These objectives may be the selection of a mining method, identifying geomechanical domains, design of excavations, selection of support, etc.

\section{5 Data collection techniques}

Although there are several standards for geomechanical data collection, these are not necessarily applied or enforced at several mining operations. The reasons for this diversity of approach, or non-compliance to site specific standards, are beyond the scope of this paper and have to do as much with the inherent material variability, economics and corporate culture. This section highlights some of the data collection techniques illustrating the issues relating to geomechanical data generation.

\subsection{Core logging}

At the early stage of data collection the first set of available information is based on core logging. This is understandable at the feasibility stage but it is somewhat surprising how these original data, often without being updated, form the basis for subsequent rock mass classification ratings. Rock mass assessment, based only on core logging can easily be off by $50 \%$ with Jakubec and Esterhuizen (2007) identifying the following limitations:

- Differentiation between artificially induced breaks and natural defects.

- Assessment of discontinuities in foliated or highly laminated rocks.

- Differentiation between continuous joints and discontinuous fractures.

- Drilling orientation bias. Missing or underestimating discontinuity sets sub-parallel to the drill hole.

- Accurate assessment of weak joint infill that is washed out in most drilling processes.

- Rock strength assessment in weathered/altered sensitive rock types such as kimberlites and mudstones.

- Material anisotropy. Assessment of both intact rock strength and discontinuity strength anisotropy from the drill core could be a problem. The core cross-section is simply too small to capture joint geometry.

Other factors that also come into play include the level of experience, interest and motivation of site personnel that undertake core logging. Although most operations are equipped to record RQD, there are several cases where there is a reluctance to diligently record RQD. Figure $5 a$ is an example of a mine diligently recording RQD, including photographic images. Figure $5 b$ is from another operation where RQD was routinely recorded by geologists by placing 10 to 15 core boxes on the ground, with a geologist "eyeballing" and recording a unique RQD. In the second case, the geologist was convinced that, given his other tasks, there was little need for more precision or effort in measuring RQD. At the same time, this deviation from standard procedures was not known by the engineering department that assumed that RQD was continuing to be diligently recorded. 

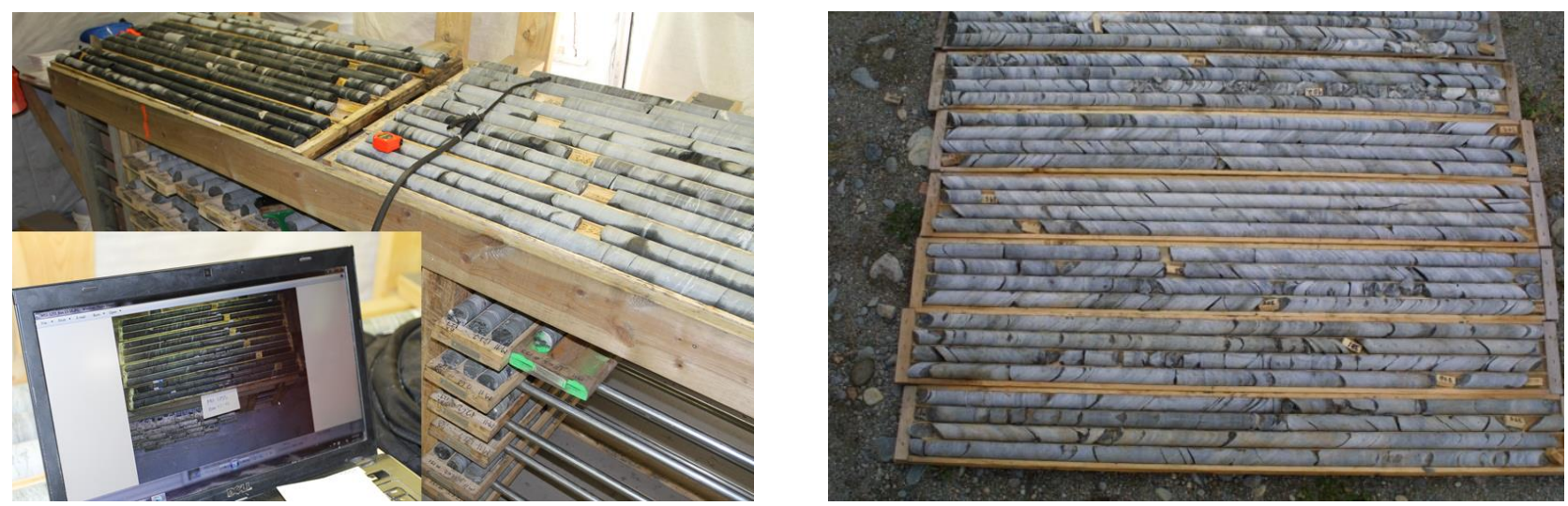

Figure 5 Two approaches of recording RQD: (left) diligently recording RQD and ( $r$ ight) "eyeballing" RQD

The reality is that we do have access to sophisticated tools to determine rock mass quality from boreholes. The use of optical and acoustical geocameras or televiewers provides a valuable tool in obtaining $360^{\circ}$, digital colour images of the walls inside a borehole and of fractures and other defects along the borehole. The use of televiewer images can be used as a means of quality control and assurance by providing a reconciliation of the recorded images to core. Figure 6a provides an example of sample optical and acoustic televiewer images in a jointed zone resulting in broken core while Figure $6 \mathrm{~b}$ shows photographed core box interval between 48.5 and $52 \mathrm{~m}$, showing broken and lost core zone.

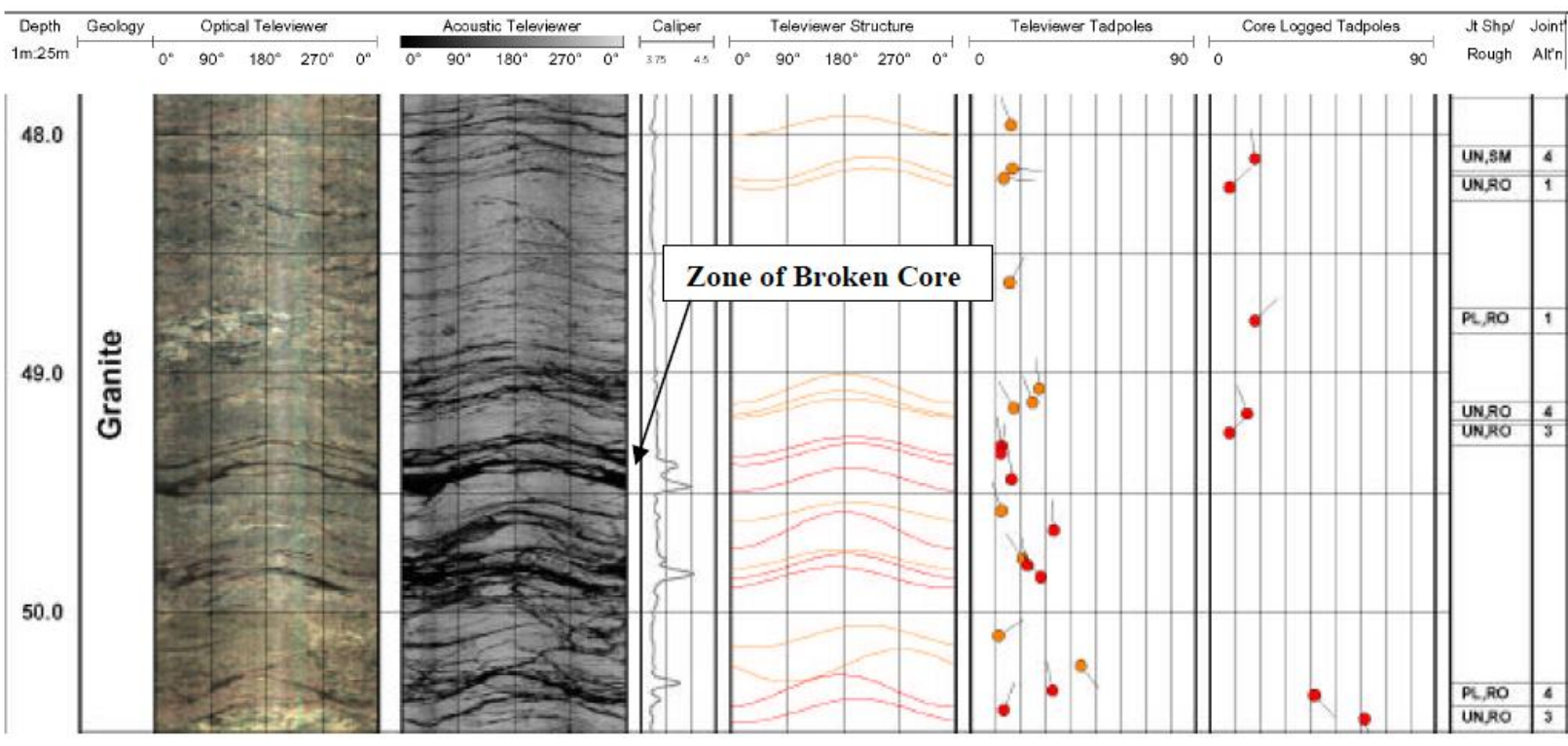

(a)

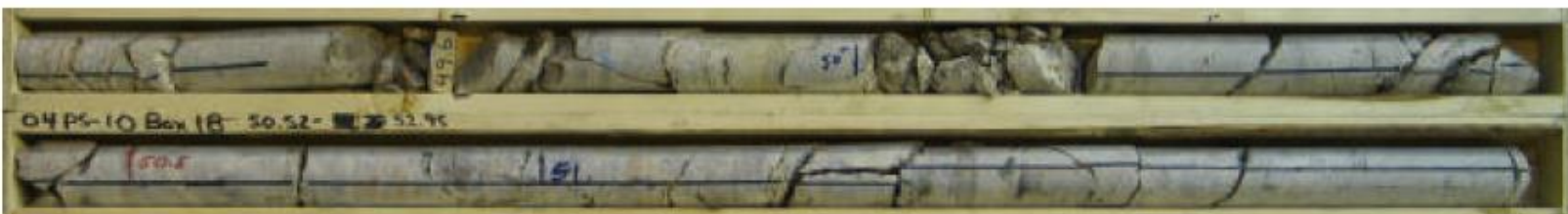

(b)

Figure 6 (a) Optical and televiewer images reconciled with photographed core, courtesy of Golder Associates Ltd; (b) Photographed core for the same length as in Figure 5 (left), courtesy of Golder Associates Ltd

Constructing reliable structural models from core is not a trivial subject, and unless explicitly requested by the design team and management, it is generally not done with the required level of detail and precision. A further concern is that most methods for determining the orientation of planar structures from drill core 
are designed to work with full core, as retrieved directly from a drill hole. In most mining and exploration circumstances, critical intervals of the core are cut in half for assay purposes, as soon as possible after drilling. There are limited approaches to determine orientation from half core, for example, the method by Blenkinsop and Doyle (2010), and it is difficult to establish how these methods are applied.

\subsubsection{Structural mapping}

Structural mapping is undertaken to identify pertinent geological structures, rock mass characterisation and generate reliable input data for stability analyses. Hadjigeorgiou et al. (1995) reviewed the various mapping methods and the need for trade-offs between the different techniques as a function of existing field conditions and intended use of data. Most statistical techniques defining the structural fabric of a rock mass are only applicable when a sufficient amount of data is available. In deep and high stress mines there is often a scarcity of quality data due to mapping difficulties such as limited access, coverage of wall exposures with shotcrete or wire-mesh, dust, poor lighting and noise. These adverse conditions are often compounded by the need to comply with strict production constraints.

Digital characterisation and laser scanning techniques can provide invaluable characterisation tools for rock exposures. Kemeny et al. (2006) provided an excellent review of digital imaging, laser-based imaging, image and stereo-vision hardware and software to characterise rock exposures and accuracy issues. These techniques offer several advantages in comparison with manual discontinuity sampling methods: (i) reduction of time and effort required for mapping; (ii) limited exposure of operators to potentially unsafe conditions; (iii) development of a permanent geomechanical database that can be consulted at any time, for example, after excavation or lining of the exposures; and (iv) greater quantity of collected data, resulting in more representative and accurate values of fracture network properties.

\subsubsection{In situ stress}

In a deep and high stress environment it is desirable to have access to quality stress data. Hudson et al. (2003) proposed a series of incremental steps that can be used in developing knowledge of the rock stress tensor components.

- Use pre-existing information on the rock stress state at the site.

- Consider whether the vertical direction is a principal stress direction (from topography, geological evidence and other information).

- Estimate the vertical stress component magnitude (from the rock density and overburden depth).

- Consider indications of the principal stress directions and the ratio of stress differences (from focal plane solutions inversion or seismic shear wave anisotropy).

- Establish the minimum principal stress orientation (whether actual or minimum horizontal stress) from hydraulic or drilling induced fractures and borehole breakout orientations.

- Find components of the stress tensor using indirect methods on borehole core (such as the Kaiser effect and differential strain analysis).

The next step would be to establish the complete stress state at one or more locations by overcoring tests or hydraulic fracturing. Undertaking in situ stress measurements is not a trivial matter, having to take into consideration practical issues including length, dip and stability of access borehole, role of water, etc., and the resources available.

Even under ideal conditions, such as Canada's URL AECL Underground Research Laboratory, the coefficient of variation for stress magnitude for high quality stress measurements at depth is in the order of $20 \%$, Martin et al. (2003). In a mining environment, the variations are expected to be higher.

An example of the difficulties in interpreting stress measurements at depth at a mine site has been provided by McKinnon and Labrie (2006) where they noted that at a particular mine site, near the Cadillac 
Fault, measurements made at 1,460 and $1,500 \mathrm{~m}$ below surface, generally conformed to expected stress levels, but stress magnitudes determined at greater depth, 2,180 and 2,190 m below surface, were lower than those determined at shallower depth. Although they did not provide a complete interpretation for these counter-intuitive results, they highlighted the problems with stress measurements at depth in a heterogeneous stress field.

\subsection{Instrumentation and monitoring}

Valuable geomechanical data can be gained from a well-designed and executed instrumentation program that aims to provide answers to specific questions. A review of all available instrumentation techniques is not within the scope of this paper. The interested reader is referred to a recent review by Eberhardt and Stead (2011) where they also addressed issues in selecting appropriate tools such as:

- Range: the maximum distance over which the measurement can be performed, with the greater range usually being obtained at the expense of resolution.

- Resolution: the smallest numerical change an instrument can measure.

- Accuracy: degree of correctness with respect to the true value is the accuracy, and it is usually expressed as a plus-or-minus number or as a percentage.

- Precision: the repeatability of similar measurements with respect to a mean, usually reflected in the number of significant figures quoted for a value.

- Conformance: whether the presence of the instrument affects the value being measured.

- Robustness: the ability of an instrument to function properly under harsh conditions to ensure that data accuracy and continuity are maintained.

- Reliability: confidence in the data; poor quality or inaccurate data can be misleading and is worse than no data.

In deep and high stress mines under a series of conditions there will be a seismic response to mining activities. Recent years have seen a change in strategy where the objective is to gain an improved understanding through monitoring. This can allow the implementation of proactive measures such as modifying mining sequence and modifying support strategies.

The mining community has recognised the need for collecting seismicity data as means to characterise if a geological structure is active, as well as monitoring rock mass degradation and fracturing. Rockburst data are extremely useful in assessing the performance of support systems, constructing re-entry protocols, etc.

This is reflected in an increase in the number of installed mine wide seismic monitoring systems worldwide. In Australia the number has reached close to 60, and in Canada close to 40 . These are attributed to deepening of existing mines, as near surface resources are exhausted and the improved understanding of the benefits of managing mine seismicity data. The quality of seismic data is dependent on several factors such as sensitivity and coverage of the monitoring system.

\section{6 Filling in the gaps}

Irrespective of the quantity of data collected there is always a need to fill in the gaps. This is often when the design tools require input parameters that were either not collected through omission, lack of foresight or simply the needs changed. Sometimes this is simply a question of the project leader or consultant who imposed their own preferences on the type of data to be collected, for example, collecting data for one classification system versus another. An example of this is the use of sophisticated stress models that often require a panoply of specific input data.

It is somewhat surprising, but in a number of deep and high stress mines there are limited stress measurements. Under these conditions they often rely on stress charts. These charts should be used with great caution as they often group data from a variety of sources. For example, even though stress regimes 
in mines located in Canada and Australia may have some similarities in terms of high horizontal stress, South African mines display entirely different conditions. Furthermore, the large dispersion in all collated data may be attributed to a variety of causes such as:

- influence of geological formation and geological structure

- quantity and spatial variation of geological structures

- properties of rock mass

- influence of zone of excavation

- problems associated with the measurement techniques, use of equipment and quality control

- interpretation errors.

Mine design, whether relying on empirical or numerical techniques, will eventually use geomechanical data as input. This is the stage that engineers realise that there are gaps in the type, quality and quantity of data required for their analysis. At this point there are two alternatives: initiating data collection campaigns or attempting to fill in the gaps of information by extrapolating material from existing data based on experience and conversions. Both options have severe limitations. A new data collection campaign will generally result in time delays, and in certain cases, access may no longer be available or core may no longer be available or potentially mishandled.

Another type of problem arises in cases where there are data available, but have already been manipulated in a format that is not suitable for the analysis. This is often the case when collected data are presented in the form of a rock mass classification system. The most usual approach, under these circumstances, is to "convert" ratings from one system to another. Examples include converting from $Q$ to RMR and from RMR to GSI and to evaluate estimates of rock mass strength.

Despite the appeal of such correlations, there is no conclusive statistical evidence that there is a universal relationship, applied across rock quality classes between $Q$ and RMR. In fact, there is no strong case that the $Q$ and RMR systems should be directly related. The assessment for intact rock strength and stress is significantly different in the two systems. Consequently, depending on the overall intact rock and discontinuity properties and spacing, different relationships between $Q$ and RMR can be expected. The limitations of correlations between systems, and parameters that claim to capture the same fracture geometrical qualities have been demonstrated in a comprehensive analysis of field data, Grenon and Hadjigeorgiou (2003). This should pose concern given the tendency to search for correlation between different systems and parameters.

Perhaps the greater source of concern is the tendency to rely on software packages, or published databases to provide the necessary geotechnical data. In the most popular packages, the user can identify a rock type and can gain access to laboratory test results, for example uniaxial or triaxial. Quite often, however, the information is provided as an "average" value with little information on the number of tests, deviations, sample description or observed failure mechanisms. The reality is that there exists a huge variety of rock masses and ground conditions requiring the application of relevant tools that represent the actual rock mass and ground conditions encountered.

Another source of error occurs where the users employ sophisticated stress modelling tools to undertake an analysis in the absence of data. Unfortunately it is not uncommon for inexperience users to rely on the default values of the software which may be completely inappropriate for a specific design. The real concern is that the results of these data limited analysis become the data for the next level analysis, often ignoring the assumptions and simplifications made due to data limitations.

\section{$4 \quad$ Management of geotechnical data}

Given the time and effort to collect geomechanical data, it is quite surprising that the process of managing data is not given greater importance. There is a wide range of methods for storing data including filing 
cabinets, notice boards, electronic files or increasingly on a company's intranet service. It is desirable that geomechanical data are shareable, transportable and secure. Furthermore, data must be continuously kept up-to-date.

An indication on how well data are managed in a mining operation is when it is possible to trace and document what happens to any geomechanical data, for example, the results of laboratory tests, as the data progresses through the various media, such as laboratory reports, Microsoft Access databases and Microsoft Excel spread sheets, mine planning software, etc. Is it possible to know what transformations and manipulations happened to that data? It should be recognised that when everyone is using their own spread sheets it becomes difficult to establish which version is the correct one.

The path forward is to establish a priori of the objectives of any geomechanical data collection program. It is necessary to issue specific guidelines and tasks and ensure that the personnel assigned to these tasks are competent. Following the initial geomechanical data collection program, the information has to be collated and verified by a quality assurance program. Once this is in place, a well-established and understood dissemination protocol must be implemented.

In any case, as pointed out by Jakubec and Laubscher (2000), efficient data management must not lose track that "....The use of spreadsheets greatly enhance our ability to quickly calculate and illustrate our results but without 'touching' the rocks and using engineering judgment conclusions based on such computerised processes could not only be misleading but dangerous."

\section{1 Solving data I imited problems}

The shift to tool driven design has led to a change in mind set and the belief that we can model complex material behaviour. This has been further advanced by gains in computer power and advancements in modelling. In the absence of quality data, this has sometimes resulted in not realistic expectations or blind faith in the results of modelling.

Starfield and Cundall (1988) used a classification proposed by Holling (1978) to demonstrate that rock mechanics fall into the class of 'data-limited' problems where relevant data are unavailable or cannot easily be obtained (Figure 7). This is quite different from other fields of engineering where we have both engineering data and a good understanding. Once this is accepted, it is possible to use different approaches to modelling than other engineering fields.

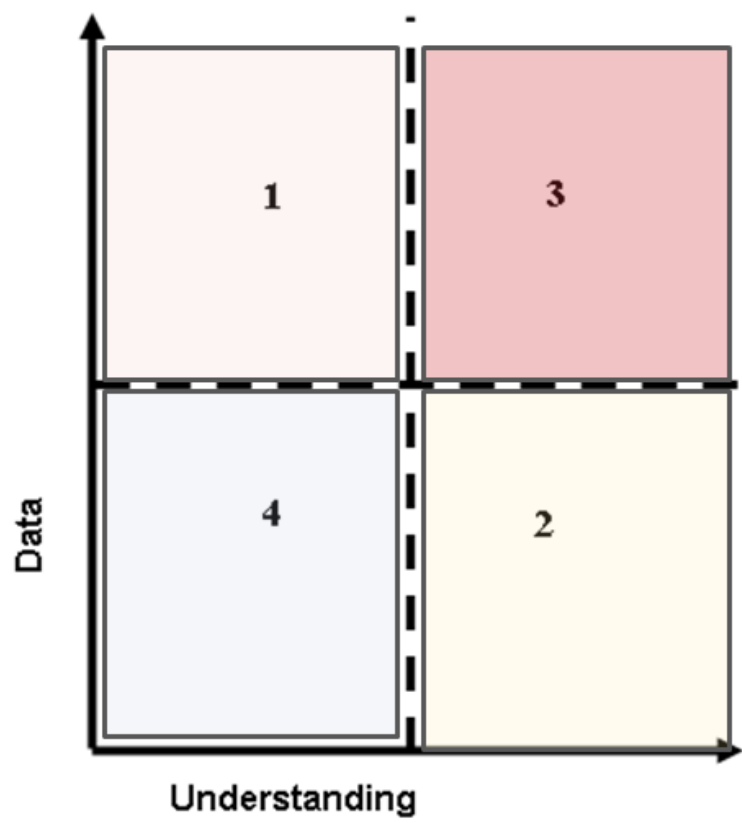

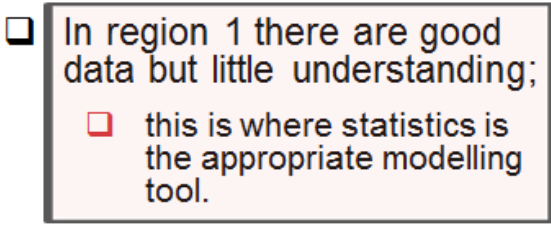

$\square$ In region 3 one has both the data and the understanding;

$\square$ models can be built, validated and used with conviction.

\section{Regions 2 and 4}

$\square$ data-limited problems

$\square$ relevant data are unavailable or cannot easily be obtained.

Figure 7 Classification of modelling problems, after Holling (1978) 
The argument made here is that simple models with limited data are still of use. In certain cases, and unless there is an effort to identify and collect the necessary geomechanical information, our most sophisticated models are limited or can be misinterpreted as more "precise" than the input data warrant. Under these circumstances, model validation and calibration become critical and is only possible if there is further effort in collecting more data whether they are visual, deformation or seismicity. This process can be aided by using the rigorous methodology for quantifying the reliability of numerical models relying on back-analysis techniques proposed by Wiles (2006). A recent calibration study relying on microseismicity data has been reported by O'Connor et al. (2010) for Creighton Deep of Vale.

\section{2 Data integration and visualisation}

Geomechanical data are most useful when analysed, processed and represented in 3D space. Increased value is derived when there is a flawless data transfer between geomechanical databases, monitoring data and modelling. This is an area where there has been considerable progress.

The advantages of this integrated approach to interpreting and visualising data has been demonstrated by Maybee et al. (2007) (Figure 8). A 3D computer integrated software Gocad $^{\mathrm{TM}}$ that included interpreted 3D lithological contacts, mine infrastructure, extraction sequence, a microseismic database and the results of a 3D stress analysis for the Thayer Lindsley Mine of Xstrata.

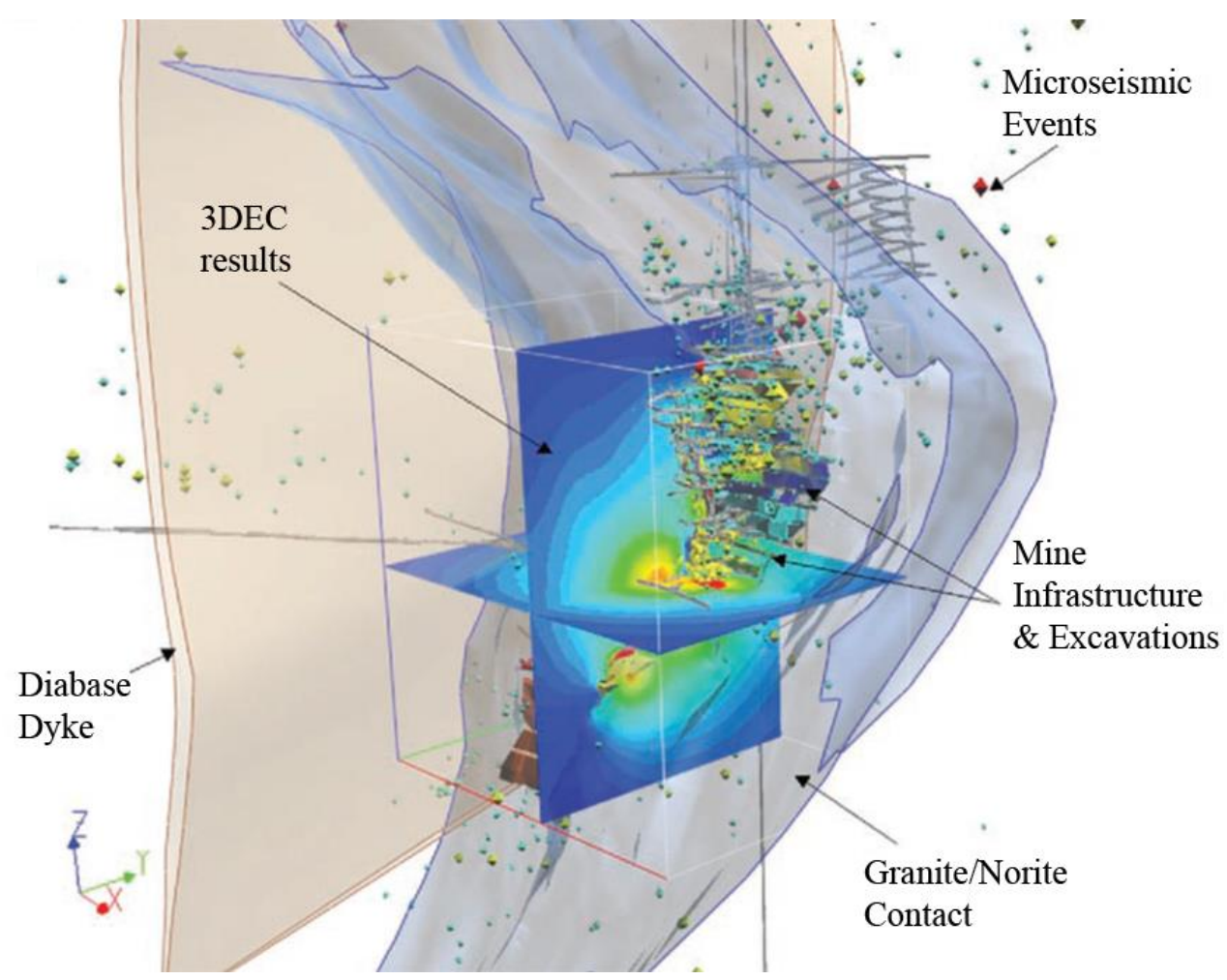

Figure 8 Typical elements comprising the computer integrated geomechanical mine modelling approach for Thayer Lindsley Mine. Isometric view of the entire mine looking approximately northwest, after Maybee et al. (2007)

\section{$5 \quad$ The role of human resources in data collection}

A major issue, often overlooked is who collects geotechnical data. The data collection process is dependent on employing and training personnel assigned to these tasks. Unless the people doing the geomechanical data collection realise how important their effort is and how useful it is to the operation, they do not assign the same level of priority as other tasks. This is often the case at the green field stage where the data collection process is driven by exploration. 
It is imperative to establish a strategy on who collects data, how qualified they are, how the information is recorded, what are the quality control measures in place etc. It is interesting that while resource estimation clearly defines what a qualified person is, there is no similar system in place for the collection of geomechanical data.

Another unaddressed issue is the common inadequate communication between geology and engineering as to what data should be collected, for what purpose and a clear demonstration that the data will be put into good use. In the early stages of a project, data are commonly collected by exploration geologists, with engineering having a greater input at later stages. The transition of the geomechanical database from geology to engineering is often complicated by different philosophies and by personnel changes.

It is a reality that people are an essential part of an organisation's memory and data management and this emphasises the need for efficient and reliable communication. It is therefore important to note the tendency to use communication channels that are less formal such as electronic mail, and the potential impact that they have on the reliability of communications.

\section{How reliable are the collected data}

Sources of error for engineering design purposes are often associated with data collection and material testing methods. In cases where data collection uses specific standardised techniques and equipment, then it can be relatively easy to quantify the magnitude of error, Hadjigeorgiou and Harrison (2011).

A recurring question when planning a rock testing program is how many samples have to be tested for any particular test to adequately describe the mechanical properties of a given rock or rock mass type. Gill et al. (2005) compiled sample sizes as suggested by the ISRM (Table 4).

Table 4 Sample sizes as suggested by the ISRM, after Gill et al. (2005)

\begin{tabular}{ll}
\hline Test Type & Sample Size \\
\hline $\begin{array}{l}\text { Uniaxial compression } \\
\begin{array}{l}\text { Direct and indirect } \\
\text { tensile strength }\end{array}\end{array}$ & $\begin{array}{l}\text { Determined from practical consideration but at least five are preferred } \\
\text { Point load test }\end{array}$ \\
$\begin{array}{ll}\text { Triaxial } & \text { At least 10, more if heterogeneous or anisotropic. The two lowest and highest } \\
\text { vhore hardness } & \text { Determined from practical consideration but at least five are preferred } \\
\text { Porosity/density } & \text { A large number }\end{array}$ \\
\hline
\end{tabular}

Gill et al. (2005), however, made a strong case that it is not possible to decide a priori of the number of required tests for a given rock type and a target precision index. Instead they proposed to establish the number of tests based on small-sampling theory. They further demonstrated that for a given rock and test type, the minimal sample size varies from one case to the other. The conclusions by Gill et al. (2005) are in direct agreement with more recent work by Ruffolo and Shakoor (2009). The latter work investigated the number of required tests to estimate the mean unconfined compressive strength of different rock types. It further established a relationship between the minimum number of samples needed, using the confidence interval approach, and the coefficient of variation (Figure 9). 


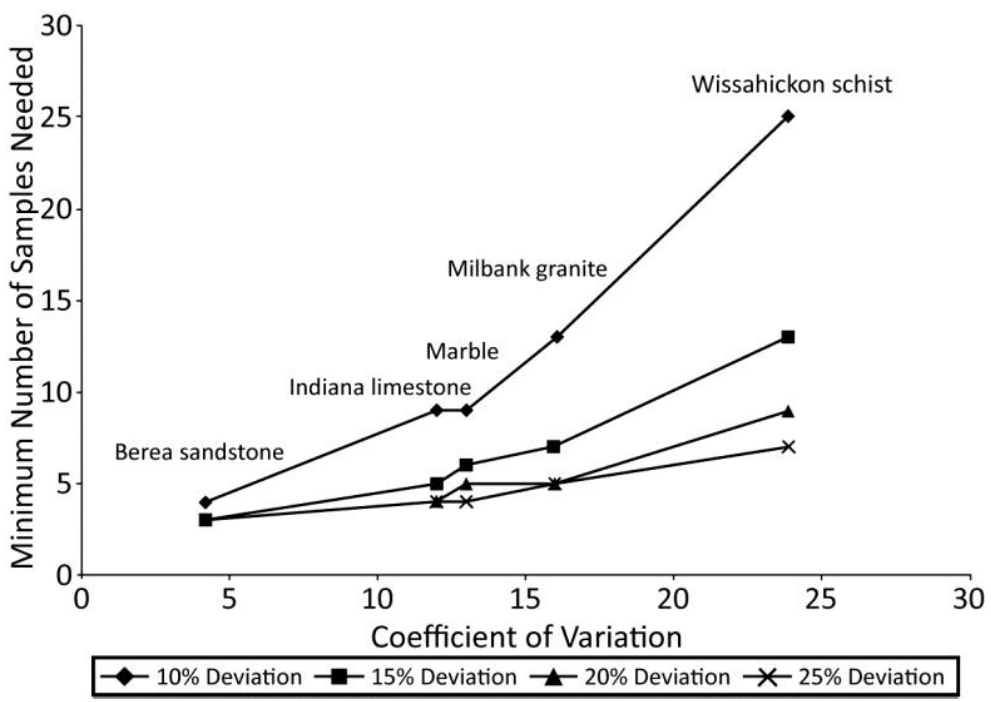

Figure 9 Minimum number of samples needed to estimate the mean unconfined compressive strength based upon the acceptable deviation from the mean and the corresponding coefficient of variation, using the confidence interval approach, after Ruffolo and Shakoor (2009)

In effect, the higher value of coefficient of variation indicates higher variability and the need for testing a higher number of samples.

Even when laboratory data are available and reliable, they are often inadequate to predict the strength of rock masses. It is commonly accepted that there is a significant reduction in strength with increasing sample size. This is often determined by degrading the strength of the intact rock as a function of rock mass quality defined by classification system, such as RMR, Q or GSI. Of course this process, while convenient, carries severe limitations including the pertinence of the employed rock classification system. An approach that merits further attention is using the Synthetic Rock Mass (SRM) of large scale samples to determine the strength of rock masses. This has been used with some success by Cundall et al. (2008), Esmaieli et al. (2010), Elmo and Stead (2010) and Mas Ivars et al. (2011). Figure 9 illustrates a generated SRM for Brunswick Mine.

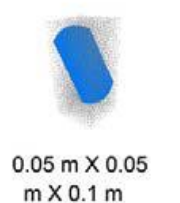
$\mathrm{m} \times 0.1 \mathrm{~m}$

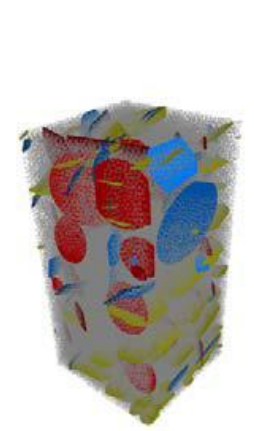

$3.5 \mathrm{~m} \times 3.5$ $\mathrm{m} \times 7.0 \mathrm{~m}$

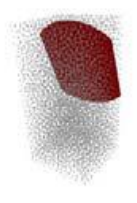

$0.2 \mathrm{~m} \times 0.2$ $\mathrm{m} \times 0.4 \mathrm{~m}$

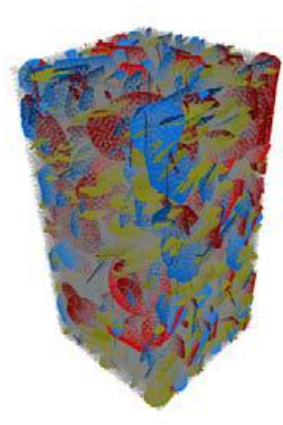

$7.0 \mathrm{~m} \times 7.0$ $\mathrm{m} \times 14.0 \mathrm{~m}$
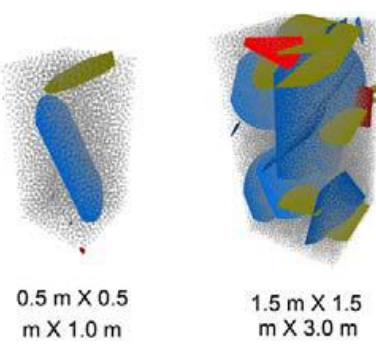

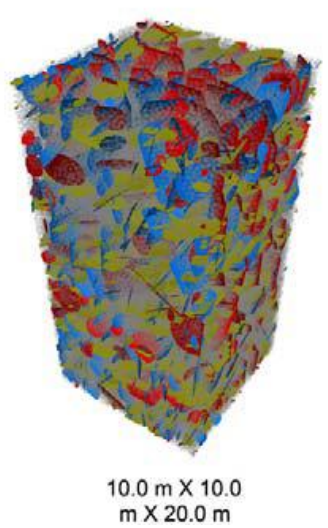

Figure 10 SRM samples generated by Iinking the PFC3D and Fracture System Models, after Esmaieli et al. (2010) 
The SRM-derived mechanical properties, at the representative elementary volume (REV) scale, were subsequently used as input parameters for mine-scale global numerical stress analysis simulations at Brunswick Mine. Although this approach is not yet widely implemented, it is promising and of interest in that it renders itself to statistical validation.

\section{$7 \quad$ Conclusions}

Collecting data is not an objective in itself. Unless they can be analysed and summarised, they are of limited use. In order to be useful, data have to be processed and converted into information. In a deep mining context it may very well be that, depending on the level of detail required, one person's information is another person's data. The process is completed when information is transformed into knowledge. This requires education and experience and a clear understanding of the processes.

It should be recognised that the use of rock mass classification systems, although convenient, is not always applicable in rock mass conditions which are neither homogeneous nor anisotropic. Consequently, there is a need to better define discrete features that may control the behaviour of a rock mass at depth.

As the engineering process advances it is necessary to validate the predictions of any employed design model. This is only possible if there are monitoring or performance data. Although the need to close the design loops from data collection, design, implementation, monitoring has been recognised for some time, there are concerns in its implementation.

Although traditional design methodologies advocate a sequential process of data collection, analysis, and geotechnical model construction followed by analysis and design, this is not really the most applicable approach in deep mining. The case is made that a more optimal approach in data collection takes place, in parallel with design. It is realised that this imposes further constraints in time and personnel and introduces a commitment to continuous data collection and modelling. Nevertheless, it is felt that the increased benefits justify such an approach.

\section{Acknow ledgements}

The author would like to acknowledge the technical input of his colleagues at several mining companies. The continued support of the Natural Science and Engineering Council of Canada is greatly appreciated.

\section{References}

Baecher, G.B. and Christian, J.T. (2003) Reliability and Statistics in Geotechnical Engineering, Wiley, 618 p.

Barton, N. (2002) Some new Q-value correlations to assist in site characterisation and tunnel design, International Journal of Rock Mechanics and Mining Sciences, Vol. 39, pp. 185-216.

Barton, N., Lien, R. and Lunde, J. (1974) Engineering classification of rock masses for the design of rock support, Rock Mechanics, Vol. 6, pp. 189-236.

Beck, D.A., Pfitzner, M.J., Arndt, S.M. and Fillery, B. (2009) Estimating rock mass properties and seismic response using higher order, discontinuous, Finite Element models, in Proceedings 3rd Canada US Rock Mechanics Symposium, M. Diederichs and G. Grasselli (eds), Toronto, on CD-Rom.

Bieniawski, Z.T. (1988) Towards a creative design process in mining, Mining Engineering, Vol. 40, pp. 1040-1044.

Bieniawski, Z.T. (1976) Rock mass classifications in rock engineering, in Proceedings Symposium on Exploration for Rock Engineering, Z.T. Bieniawski (ed.), A.A. Balkema (eds), Rotterdam, pp. 97-106.

Bieniawski, Z.T. (1989) Engineering rock mass classifications, John Wiley \& Sons, New York, 251 p.

Bieniawski, Z.T. (1992) Principles of engineering design for rock mechanics, in Proceedings 33rd US Symposium on Rock Mechanics, J.R. Tillerson and W.R. Wawersik (eds), Balkema, pp. 1031-1040.

Blenkinsop, T.G. and Doyle, M.G. (2010) A method for measuring the orientations of planar structures in cut core, Journal of Structural Geology, Vol. 32, pp. 741-745.

Bullock, R.L. (2011) Mineral Property Feasibility Studies, Chapter 4.7 - SME Mining Engineering Handbook, P. Darling P. (ed.), 3rd edition, pp. 227-261.

CIM (2005) CIM Standards on Mineral Resources and Reserves, The CIM Standing Committee On Reserve Definitions.

Corthésy, R., Gill, D.E. and Leite, M.H. (1998) Élaboration d'un modèle de prédiction des contraintes dans la région de la faille de Cadillac, CIM Bulletin, The Canadian Institute of Mining, Metallurgy and Petroleum (CIM), Vol. 91 (1020), pp. 54-58. 
Cosgrove, J.W. and Hudson, J.A. (2011) The structural geology contribution to rock mechanics modelling and rock engineering design, Harmonising Rock Engineering and the Environment - Q. Qian and X. Zhou (eds), pp. 195-199.

Cundall, P.A., Pierce, M.E. and Mas Ivars, D. (2008) Quantifying the Size Effect of Rock Mass Strength, in Proceedings First Southern Hemisphere International Rock Mechanics Symposium (SHIRMS), Y. Potvin, J. Carter, A. Dyskin and R. Jeffrey (eds), Vol. 2 Fundamental and Petroleum, 16-19 September 2009, Perth, Australia, Australian Centre for Geomechanics, Perth, pp. 3-15.

Doyle, A.C. (1892) A Scandal in Bohemia, in The Adventures of Sherlock Holmes, p. 307.

Dubé, B., Mercier-Langevin, P., Lafrance, B., Hannington, M., Moorhead, J., Davis, D. and Pilote, P. (2003) The Doyon-BousquetLaRonde Archean Au-rich VMS gold camp: The example of the world-class LaRonde deposit, Abitibi and its implications for exploration, Keynote talk at the CIM Timmins, Field conference, Ore deposits at depth: Challenges and opportunities; September 23-26, Technical Sessions Abstract Volume, pp. 3-10.

Eberhardt, E. and Stead, D. (2011) Geotechnical Instrumentation, Chapter 8.5 in SME Mining Engineering Handbook, Darling P. (ed), 3rd Edition, pp. 551-571.

Elmo, D. and Stead, D. (2010) An Integrated Numerical Modelling-Discrete Fracture Network Approach Applied to the Characterisation of Rock Mass Strength of Naturally Fractured Pillars, Rock Mechanics Rock Engineering, Vol. 43, pp. 3-19.

Elmo, D., Rogers, S. and Beddoes, R. (2011) Numerical analysis of caving mechanism using a hybrid FEM/DEM approach: experience gained and lessons learned, 45th US Rock Mechanics/Geomechanics Symposium held in San Francisco, CA, ARMA 11-323.

Esmaieli, K., Hadjigeorgiou, J. and Grenon, M. (2010) Estimating geometrical and mechanical REV based on synthetic rock mass models at Brunswick Mine, International Journal of Rock Mechanics and Mining Sciences, Vol. 47, pp. 915-926.

Gill, D.E., Corthésy, R. and Leite, M.H. (2005) Determining the minimal number of specimens for laboratory testing of rock properties, Engineering Geology, Vol. 78, pp. 29-51.

Golder Associates (2009) FracMan Workbook.

Grenon, M. and Hadjigeorgiou, J. (2003) Evaluating Discontinuity Network Characterization Tools through Mining Case Studies, Soil Rock America, Boston, Vol. 1, pp. 137-142.

Grenon, M. and Hadjigeorgiou, J. (2003) Drift reinforcement design based on discontinuity network modeling. International Journal of Rock Mechanics and Mining Sciences, Vol. 40, pp. 833-845.

Hadjigeorgiou, J. and Harrison, J.P. (2011) Uncertainty and Sources of Error in Rock Engineering, ISRM Congress of Rock Mechanics, Harmonising Rock Engineering and the Environment, Q. Qian and X. Zhou X. (eds), Beijing, pp. 2063-2067.

Hadjigeorgiou, J., Esmaieli, K. and Grenon, M. (2009) Stability analysis of vertical excavations in hard rock by integrating a fracture system into a PFC model. Tunnelling and Underground Space Technology, Vol. 24, pp. 296-308.

Hadjigeorgiou, J., Lessard, J.F. and Flament, F. (2005). Characterizing in-situ block size distribution using a stereological model. Canadian Tunnelling, The Tunnelling Association of Canada, pp. 111-121.

Hadjigeorgiou, J., Lessard, J.F., Villaescusa, E. and Germain, P. (1995) An Appraisal of Structural Mapping Techniques, Second International Conference on Mechanics of Jointed and Faulted Rock, Vienna, Balkema, pp. 191-198.

Haile, A. (2004) A Reporting Framework for Geotechnical Classification of Mining Projects, The AusIMM Bulletin, Vol. 5 (September/October), pp. 30-37.

Hoek, E. (1994) The Challenge of Input Data for Rock Engineering, Letter to the Editor, ISRM News Journal, Vol. 2, No. 2, pp. $23-24$.

Holling, C.S. (ed) (1978) Adaptive Environmental Assessment and Management, Wiley, Chichester.

Hudson, J.A., Cornet, F.H. and Christiansson, R. (2003) ISRM Suggested Methods for rock stress estimation-Part 1: Strategy for rock stress estimation, International Journal of Rock Mechanics and Mining Sciences, Vol. 40, pp. 991-998.

Jakubec, J. and Esterhuizen, G.S. (2007) Use of The Mining Rock Mass Rating (MRMR) Classification: Industry Experience, in Proceedings International Workshop on Rock Mass Classification in Underground Mining, C. Mark, R. Pakalnis, R.J. Tuchman (eds), NIOSH Information Circular 9498, pp. 73-78.

Jakubec, J. and Laubscher, D.H. (2000) The MRMR Rock Mass Rating Classification System in Mining Practice, in Proceedings MassMin 2000, G. Chitombo (ed), 29 October to 2 November 2000, Brisbane, Australia, Australasian Institute of Mining and Metallurgy, Melbourne, pp. 413-421.

JORC (2004) Australasian Code for Reporting of Mineral Resources and Ore Reserves (The JORC Code), The Joint Ore Reserves Committee of the Australasian Institute of Mining and Metallurgy, Australian Institute of Geoscientists and Minerals Council of Australia.

Kemeny, J., Turner, K. and Norton, B. (2006) LIDAR for Rock Mass Characterization: Hardware, Software, Accuracy and BestPractices, Laser and Photogrammetric Methods for Rock Face Characterization, F. Tonon and J. Kottenstette (eds), Golden, Colorado.

Marinos, P.G., Marinos, V. and Hoek, E. (2007) The Geological Strength Index (GSI): A Characterization Tool For Assessing Engineering Properties For Rock Masses, in Proceedings International Workshop on Rock Mass Classification in Underground Mining, C. Mark, R. Pakalnis, R.J. Tuchman (eds), NIOSH Information Circular 9498, pp. 87-94.

Martin, C.D., Kaiser, P. and Christiansson, R. (2003) Stress, instability and design of underground excavations, International Journal of Rock Mechanics and Mining Sciences \& Geomechanics Abstracts, Vol. 40, pp. 1027-1047.

Mas Ivars, D., Pierce, M.E., Darcel, C., Reyes-Montes, J., Potyondy, D.O., Young, R.P. and Cundall, P.A. (2011) The Synthetic Rock Mass Approach for Jointed Rock Mass Modelling, International Journal of Rock Mechanics and Mining Sciences \& Geomechanics Abstracts, Vol. 48, pp. 219-244.

Maybee, G., Sampson-Forsythe, A., Cotesta, L. and O'Connor, C. (2007) Geomechanical Challenges at Xstrata Nickel's Thayer Lindsley Mine, in Challenges in Deep and High Stress Mining, Y. Potvin, J. Hadjigeorgiou and D. Stacey (eds), Australian Centre for Geomechanics, Perth, Chapter 27, pp. 233-239. 
McKinnon, S.D. and Labrie, D. (2006) Interpretation of Stresses Adjacent to the Cadillac Fault Assuming Marginal Large-Scale Rock Mass Stability, International Symposium on In-Situ Rock Stress, Trondheim, Norway, 19-21 June, M. Lu, C.C. Li, H. Kjørholt and H. Dahle (eds), Taylor \& Francis, pp. 419-428.

Mercier-Langevin, F. and Hadjigeorgiou, J. (2011) Towards a better understanding of squeezing potential in hard rock mines, AusIMM, Mining Technology, Vol. 120, No. 1, pp. 36-44.

O'Connor, C., Cotesta, L., Brummer, R. and Thibodeau, D. (2010) Non-linear modelling calibration process for Vale nickel mines Ontario division, in Proceedings Fifth International Seminar on Deep and High Stress Mining (Deep Mining 2010), M. Van Sint Jan and Y. Potvin (eds), 6-8 October 2010, Santiago, Chile, Australian Centre for Geomechanics, Perth, pp. 521-535.

Pine, R.J., Coggan, J.S., Flynn, Z.N. and Elmo, D. (2006) The development of a new numerical modelling approach for naturally fractured rock masses. Rock Mech Rock Eng 39(5), pp. 395-419.

Ruffolo, R.M. and Shakoor, A. (2009) Variability of unconfined compressive strength in relation to number of test samples, Engineering Geology, Vol. 108, pp. 16-23.

Stacey, T.R. (2004) The link between the design process in rock engineering and the code of practice to combat rock fall and rockburst accidents, The Journal of The South African Institute of Mining and Metallurgy, pp. 29-34.

Stacey, T.R. (2009) Design-a strategic issue, The Southern African Institute of Mining and Metallurgy, Vol. 109, pp. $157-162$.

Starfield, A.M. and Cundall, P.A. (1988) Towards a Methodology for Rock Mechanics Modelling. International Journal of Rock Mechanics and Mining Sciences \& Geomechanics Abstracts, Vol. 25, No. 3, pp. 99-106.

Stille, H. and Palmström, A. (2003) Classification as a tool in rock engineering, Tunnelling and Underground Space Technology, Vol. 18, pp. 331-345.

Wiles, T.D. (2006) Reliability of numerical modelling predictions, International Journal of Rock Mechanics and Mining Sciences, Vol. 43, pp. 454-472. 
